\title{
Effects of Black Pepper (Piper nigrum L.) Chloroform Extract on the Enzymatic Activity and Metabolism of Escherichia coli and Staphylococcus aureus
}

\author{
Wenxue Chen $\left(\mathbb{D},{ }^{1}\right.$ Lan Zou, ${ }^{2}$ Weijun Chen $\left(\mathbb{D},{ }^{1}\right.$ Yueying Hu, ${ }^{3}$ and Haiming Chen $\left(\mathbb{D}{ }^{1}\right.$ \\ ${ }^{1}$ College of Food Science and Technology, Hainan University, Haikou, Hainan 570228, China \\ ${ }^{2}$ Qianxinan Institution for Food and Drug Inspection Center, Xingyi, Guizhou 562400, China \\ ${ }^{3}$ College of Material and Chemical Engineering, Hainan University, Haikou, Hainan 570228, China \\ Correspondence should be addressed to Haiming Chen; hmchen168@126.com
}

Received 30 September 2017; Revised 11 December 2017; Accepted 10 January 2018; Published 5 February 2018

Academic Editor: Frederick Adzitey

Copyright (C) 2018 Wenxue Chen et al. This is an open access article distributed under the Creative Commons Attribution License, which permits unrestricted use, distribution, and reproduction in any medium, provided the original work is properly cited.

\begin{abstract}
The chemical composition and antimicrobial mechanism of action of black pepper chloroform extract (BPCE) were investigated, as well as the potential antibacterial activities of BPCE against Escherichia coli and Staphylococcus aureus. The results showed that $1 \mathrm{H}$-Cycloprop[e] azulen-7-ol, decahydro-1,1,7-trimethyl-4-methylene-, [1ar-(1a $\alpha, 4 \mathrm{a} \alpha, 7 \beta, 7 \mathrm{a}, \beta, 7 \mathrm{~b} \alpha$.)]- (8.39\%) and 2-methylene4,8,8-trimethyl-4-vinyl-bicyclo[5.2.0]nonane (6.92\%) were identified as the two primary components of BPCE. The release of intracellular transaminases from bacteria after being incubated with BPCE revealed that the bacterial cell walls and membranes were degraded and that protein synthesis was inhibited to some extent. The inhibition of bacterial $\mathrm{Na}^{+} / \mathrm{K}^{+}$-ATPase activity upon the addition of BPCE also indicated an enhanced permeability of bacterial cell membranes. Moreover, an analysis of hexokinase and pyruvate kinase activities showed that BPCE affected the metabolic rate of glycolysis and disrupted the normal metabolism of bacteria. This phenomenon was supported by an observed accumulation of lactic acid (LA) in the treated bacterial cells. Overall, our results indicated that BPCE damaged bacterial cell walls and membranes, which was followed by a disruption of bacterial cell respiration.
\end{abstract}

\section{Introduction}

Natural antimicrobial agents are increasingly being used in food industries because of the serious health risks that chemical preservatives pose [1]. Plant essential oils exhibit various antibacterial activities. For instance, essential oils from oregano, thyme, and marjoram contain many active compounds that have good antimicrobial activities against gram-positive and gram-negative bacteria $[2,3]$. China is very rich in endogenous aromatic and medicinal plants, which are used as natural health care products in traditional medicine. A number of these plants have been investigated for their biological and antibacterial activities, such as Buddleia officinalis Maxim, Osmanthus fragrans, and clove [4,5]. Since ancient times, black pepper has been commonly used as spice in cooking. Moreover, black pepper is highly valued in folk medicine because of its antibacterial and physiological benefits, particularly in treating pain, the flu, muscle aches, and rheumatism [6-8].

Recent studies have shown that black pepper extracts can inhibit food spoilage and food pathogens [9-13]. We previously explored the optimum extraction process for black pepper using chloroform and investigated the inhibitory effects and minimal inhibition concentration (MIC) of black pepper chloroform extract (BPCE) against Escherichia coli and Staphylococcus aureus. However, the antibacterial mechanisms of action of BPCE against these strains remain unclear.

Therefore, in the present study, we evaluated the antibacterial mechanism of action of BPCE against $E$. coli and $S$. aureus. Furthermore, we analyzed the modulation of key metabolic enzyme activities and assessed the leakage of the intracellular constituents of bacterial cells after being incubated with BPCE. Finally, to analyze the respiration of 
bacterial strains, we examined the lactic acid (LA) content in bacterial cells.

\section{Materials and Methods}

2.1. Materials and Chemicals. The black pepper used in this study was purchased from Nanguo Supermarket (Haikou, China), grown in Wanning, Hainan province, China, and picked in June 2016 (nine months after flowering). Hexokinase $(\mathrm{HK})$, pyruvate kinase $(\mathrm{PK})$ and $\mathrm{Na}^{+} / \mathrm{K}^{+}$-ATPase assay kits were purchased from Nanjing JianCheng Bioengineering Institute (Nanjing, China). LA was purchased from Sigma-Aldrich Chemical Co. (St. Louis, MO), and 2,4dinitrophenylhydrazine (DNP) was purchased from Aladdin Industrial Corporation. All other chemicals used in this study were purchased from Sinopharm Chemical Reagent Co., Ltd. (Shanghai, China).

2.2. Bacterial Strains. E. coli (ATCC8739) and S. aureus (ATCC6538) were provided by our laboratory. Both strains were cultured at $37^{\circ} \mathrm{C}$ for $24 \mathrm{~h}$ on nutrient agar medium, which contained $3.0 \mathrm{~g}$ of beef extract, $10.0 \mathrm{~g}$ of peptone, $5.0 \mathrm{~g}$ of $\mathrm{NaCl}$, and $15.0 \mathrm{~g}$ of agar in $1000 \mathrm{~mL}$ of deionized water, with the $\mathrm{pH}$ adjusted to 7.2-7.3. Next, the bacteria were washed twice with $0.9 \%$ sterile $\mathrm{NaCl}$ and resuspended in $9 \mathrm{~mL}$ of the same $\mathrm{NaCl}$ solution. Bacterial suspensions were prepared at a density of $1-2 \times 10^{7} \mathrm{cfu} / \mathrm{mL}$ in $0.9 \%$ sterile $\mathrm{NaCl}$, after which $1.0 \mathrm{~mL}$ of an E. coli or S. aureus suspension was added to $48 \mathrm{~mL}$ of nutrient broth medium. BPCE (predissolved in ethanol) was added to the treatment group to determine the final MIC concentrations. The control group was provided an equivalent volume ethanol without BPCE. Both groups were incubated at $37^{\circ} \mathrm{C}$ and shaken at $130 \mathrm{rpm}$.

\subsection{Preparation of Black Pepper Chloroform Extract (BPCE).} Black pepper powder (100 g) was immersed and stirred in $2 \mathrm{~L}$ of $80 \%$ ethanol at $50^{\circ} \mathrm{C}$ for $12 \mathrm{~h}$. This process was repeated three times according our previous study. The mixture was then filtered, and the solvent of the combined extracts was vacuum evaporated using a rotary vacuum evaporator ( $R V$ 10 , IKA, Germany) $\left(0.098 \mathrm{MPa}, 50^{\circ} \mathrm{C}\right)$. The remaining water was evaporated at $50^{\circ} \mathrm{C}$ in a thermostat-controlled water bath. BPCE was prepared according to our previous study [14]. Briefly, $100 \mathrm{~mL}$ of distilled water was added to the dried extract to obtain a turbid suspension. Next, $100 \mathrm{~mL}$ of petroleum ether was added to the suspension in a separatory funnel. The lower turbid suspension was transferred into another separatory funnel, after which $100 \mathrm{~mL}$ of chloroform was added to perform the extraction. Finally, the black pepper dissolved in chloroform was collected and concentrated, and the BPCE was obtained and stored at $4^{\circ} \mathrm{C}$ for further analysis.

2.4. Determination of Transaminase Activities. The activities of alanine transaminase (ALT) and aspartate transaminase (AST) in soluble fractions of cell lysates were measured. The treatment and control group samples were centrifuged at $4^{\circ} \mathrm{C}$ $(21,621 \mathrm{~g}, 10 \mathrm{~min})$. Supernatants were obtained and collected in ice until transaminase measurements were made using the classical Reitman-Frankel colorimetric endpoint reaction (Lv, 1967). Subsequently, $0.5 \mathrm{~mL}$ of ALT substrate [containing Lalanine $(0.2 \mathrm{~mol} / \mathrm{L}), \alpha$-ketoglutarate $(2.0 \mathrm{mmol} / \mathrm{L})$, and phosphate buffer $(0.1 \mathrm{~mol} / \mathrm{L}, \mathrm{pH} 7.4)$ ] and AST substrate [containing L-aspartate $(0.2 \mathrm{~mol} / \mathrm{L}), \alpha$-ketoglutarate $(2.0 \mathrm{mmol} / \mathrm{L})$, and phosphate buffer $(0.1 \mathrm{~mol} / \mathrm{L}, \mathrm{pH} 7.4)]$ were transferred into test tubes and incubated in a water bath at $37^{\circ} \mathrm{C}$ for $5 \mathrm{~min}$. Supernatants $(0.1 \mathrm{~mL})$ were added to the test tubes, mixed, and incubated in a water bath at $37^{\circ} \mathrm{C}$ for 30 or $60 \mathrm{~min}$ for ALT and AST assays, respectively. Next, $0.5 \mathrm{~mL}$ DNP $(0.1 \mathrm{mmol} / \mathrm{L})$ was added and the reactions were mixed and incubated for another $20 \mathrm{~min}$ at $37^{\circ} \mathrm{C}$. Subsequently, $5 \mathrm{~mL}$ of $\mathrm{NaOH}(0.5 \mathrm{~mol} / \mathrm{L})$ was added as color developer and mixed after heating the mixture in a water bath at $37^{\circ} \mathrm{C}$ for $10 \mathrm{~min}$. The absorbance was measured at $505 \mathrm{~nm}$ after the mixture was cooled at room temperature for $10 \mathrm{~min}$. The ALT and AST activities were calculated using a pyruvic acid calibration curve.

2.5. ATPase Activity and Key Enzymes Activities in Glycolysis Pathway. The $\mathrm{Na}^{+} / \mathrm{K}^{+}$-ATPase, $\mathrm{HK}$, and $\mathrm{PK}$ activities were assessed using the appropriate assay kits. Bacterial cells were collected by centrifugation at $4^{\circ} \mathrm{C}(21,621 \mathrm{~g}, 10 \mathrm{~min})$, then washed thrice, and resuspended in phosphate-buffered saline solution $(0.1 \mathrm{~mol} / \mathrm{L}, \mathrm{pH} 7.4)$. Bacterial cells were lysed with lysozyme $(2 \mathrm{~g} / \mathrm{L})$ in a water bath for $10-20 \mathrm{~min}$ at $37^{\circ} \mathrm{C}$ until the bacteria aggregated, after which samples were immediately placed in an ice bath and $1 \mathrm{~mL}$ of Tris-SDS was added. Cell debris was removed by centrifugation at $21,621 \mathrm{~g}$ for $10 \mathrm{~min}$ at $4^{\circ} \mathrm{C}$. Supernatants were collected and stored on ice prior to ATPase, $\mathrm{HK}$, and PK measurements.

2.6. LA Content Determination. LA was measured by highperformance liquid chromatography (HPLC) according to the methodology described by Soria and Audisio [15]. Cell free supernatants were centrifuged at $4^{\circ} \mathrm{C}(17,297 \mathrm{~g}, 10 \mathrm{~min})$, filter sterilized $(0.22 \mu \mathrm{m})$, and maintained at $4^{\circ} \mathrm{C}$ until used. The supernatants were deproteinized prior to the assay [16]. Samples $(1 \mathrm{~mL})$ were added to $2 \mathrm{~mL}$ of $\mathrm{Ba}(\mathrm{OH})_{2}(1.8 \%)$ and $2 \mathrm{~mL}$ of $\mathrm{ZnSO}_{4}$ (2\%). Next, the mixture was centrifuged, and each supernatant was filter sterilized $(0.22 \mu \mathrm{m})$ before the HPLC analyses. HPLC was performed using a Waters Alliance 2695 system (USA) equipped with a 2489 UV detector (Milford, MA, USA) connected in series with a Thermo Betasil $\mathrm{C}_{18}$ chromatography column $(300 \times 7.8 \mathrm{~mm})$. The HPLC conditions used were as follows: column temperature $30^{\circ} \mathrm{C}$; ratio of $0.1 \%$ orthophosphoric acid and methanol used for the mobile phase $99: 1$; and flow rate $0.5 \mathrm{~mL} / \mathrm{min}$. The injection volume was $20 \mu \mathrm{L}$.

2.7. GC-MS Analysis. The chemical composition of BPCE was determined by gas chromatography-mass spectrometry (GCMS). GC-MS experiments were performed on an Agilent Technologies 7890A gas chromatograph (Santa Clara, CA) and an Agilent 7683B autoinjector coupled with a 240 Agilent Ion Trap mass spectrometer (MS/MS). The mass spectral scan rate was 2.86 scans/s. The GC was operated with a helium (ultrahigh purity) flow rate of $0.7 \mathrm{~mL} / \mathrm{min}$ under a 


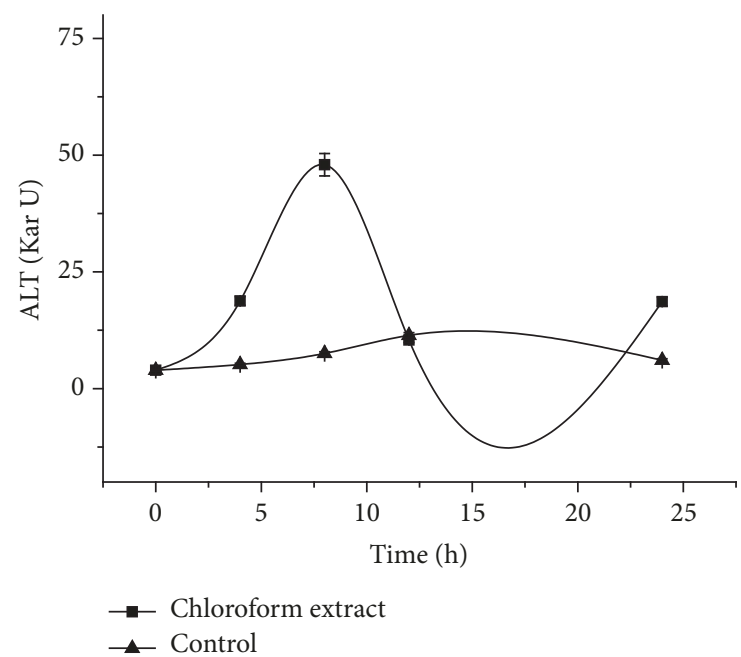

(a)

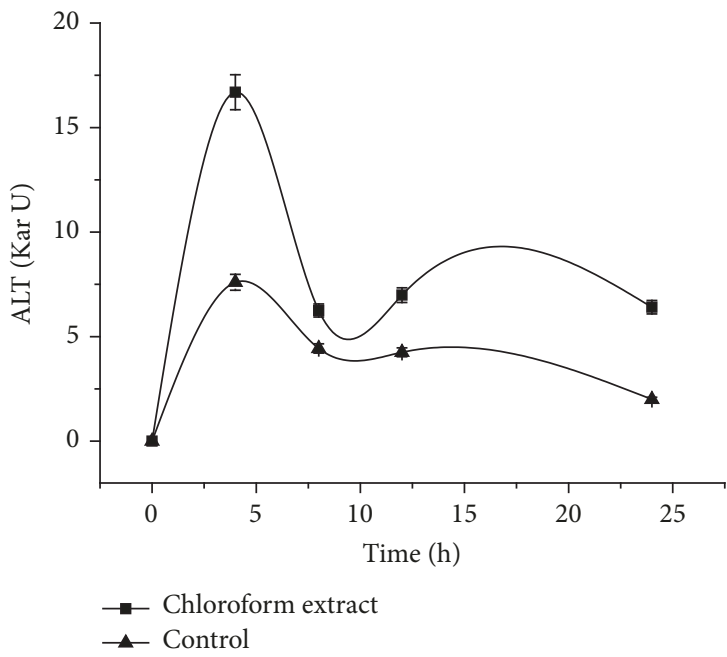

(c)

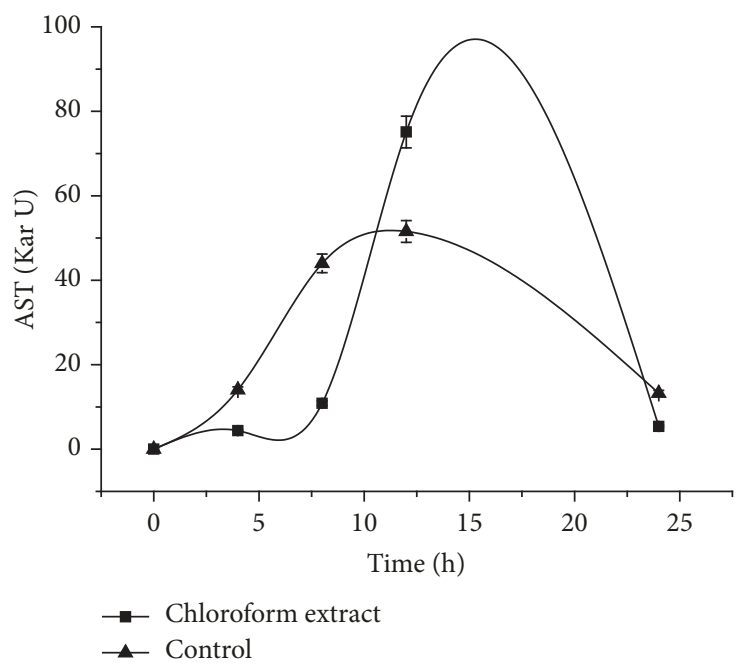

(b)

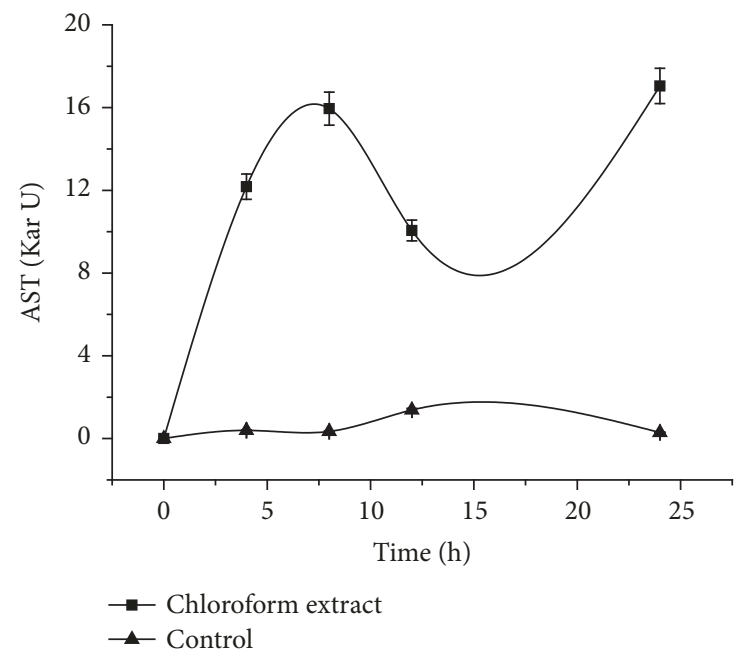

(d)

Figure 1: Transaminase activities in E. coli (a, b) and S. aureus (c, d).

head pressure of $10 \mathrm{psi}$, and the injection volume of $1 \mu \mathrm{L}$. The MS was operated in the electron ionization (EI) mode using an ionization voltage of $70 \mathrm{eV}$ and a source temperature of $230^{\circ} \mathrm{C}$. The scan type used was the automated method development function (AMD) and the optimum MS/MS excitation amplitude was $1.20 \mathrm{~V}$. Relative percentages of the primary components were calculated by integrating the registered peaks.

2.8. Statistical Analysis. All experiments were performed in triplicate. Data are presented as the means \pm SD. Data were analyzed with SAS 9.0, and significance was assessed using Duncan's one-way multiple comparison. Differences between groups were considered significant at $p \leq 0.05$.

\section{Results and Discussion}

3.1. Transaminase Activities. Transaminase is an endoenzyme that catalyzes a reaction between an amino acid and $\alpha$ ketoglutaric acid and is often used as a general indicator of bacterial injury [17]. The ALT activity in the treatment group was higher than that of the control within the initial $12 \mathrm{~h}$. However, the AST activity in the treatment group was lower than that of control at $12 \mathrm{~h}$ for E. coli (Figures 1 (a) and 1(b)). The activities of transaminases for $S$. aureus samples were lower in the control culture without the BPCE treatment (Figures 1(c) and 1(d)). By contrast, the control group slightly changed, particularly for AST. Under normal physiological conditions, the intracellular enzymes will not release from the cell. It illustrates the cell wall and cell membrane are injured, once the intracellular enzyme was determined in the extracellular fluid $[18,19]$. The current results indicated that the overall cellular structure was damaged by the leakage of transaminase, which may have been caused by BPCE. Recent studies have shown that a number of essential oils affect fungal cell permeability by directly interacting with the cytomembrane [20-22]. Using extracellular ALT and AST activities as indicators of membrane damage, the membrane structure of the bacteria was observed to be significantly 


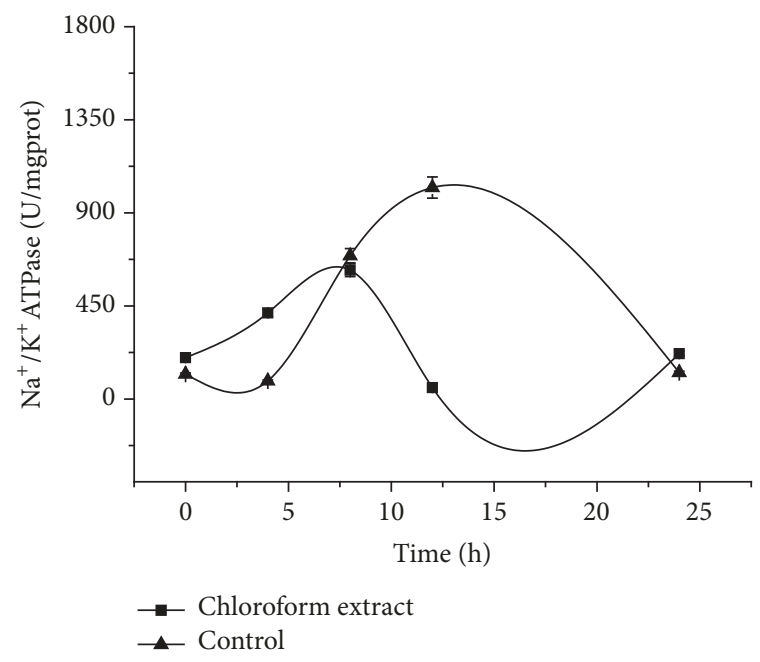

(a)

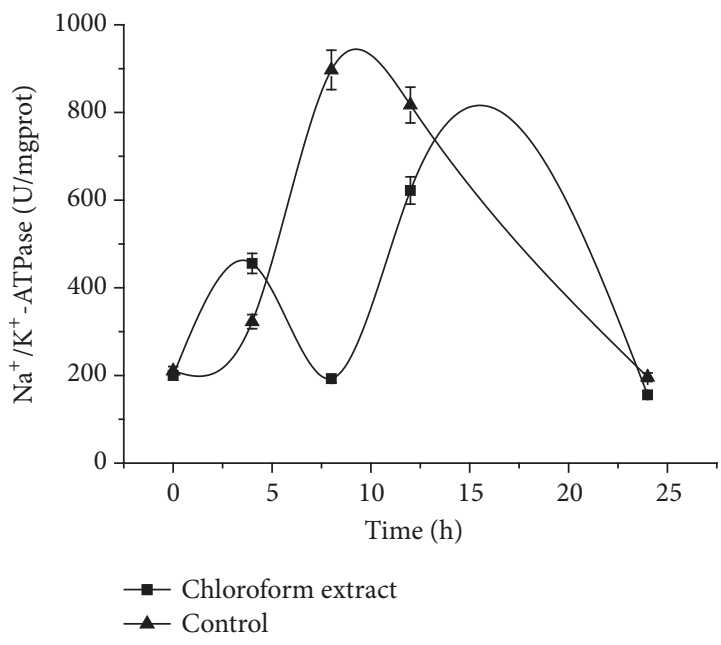

(b)

FIgURE 2: ATPase activity in E. coli (a) and S. aureus (b).

damaged by BPCE, especially for $S$. aureus. The MICs of BPCE for E. coli and S. aureus were $2.5 \mathrm{mg} / \mathrm{mL}$. In addition, transaminases disrupt the normal degradation and synthesis of cell peptides and proteins.

3.2. $\mathrm{Na}^{+} / \mathrm{K}^{+}$-ATPase Activity. $\mathrm{Na}^{+} / \mathrm{K}^{+}$-ATPase is a common sodium pump in the membrane of eukaryotic cells and is important for establishing and maintaining high $\mathrm{K}^{+}$and reducing $\mathrm{Na}^{+}$concentrations in the cytoplasm [23]. An electrochemical gradient for $\mathrm{Na}^{+}$across the plasma membrane is essential for diverse cellular functions, such as the loss of DNA, polysaccharide, and ions, inhibition of nutrient absorption, and $\mathrm{pH}$ regulation $[24,25]$. Figure 2(a) shows that the $\mathrm{Na}^{+} / \mathrm{K}^{+}$-ATPase activity in the control increased for $12 \mathrm{~h}$, whereas ATPase activity increased from 0 to $8 \mathrm{~h}$ and then decreased from 8 to $12 \mathrm{~h}$ before increasing again from 12 to $24 \mathrm{~h}$ when treated with BPCE. In the control groups, the high activity of $\mathrm{Na}^{+} / \mathrm{K}^{+}$-ATPase observed may due to bacterial growth during the initial $12 \mathrm{~h}$, at which time cells require more nutrition and energy. In addition, a certain amount of time is required for ethanol to kill bacterial cells, which cannot affect the activity of $\mathrm{Na}^{+} / \mathrm{K}^{+}$ATPase. When the bacterial culture was in the stationary phase and the death phase, most of the bacteria gradually died, and the $\mathrm{Na}^{+} / \mathrm{K}^{+}$-ATPase activity decreased, with the same rationale applying to the test groups. Moreover, the decreased ATP level is also probably due to excessive cell apoptosis and excessive ATP consumption, because apoptosis is an ATP-dependent process [26]. Figure 2(b) illustrates that the control and treatment groups demonstrated similar changing trends compared with Figure 2(a). ATPase activity was reduced when BPCE was added from 8 to $24 \mathrm{~h}$. These results indicated the degradation of the cell membrane and inhibition of ATPase in the presence of BPCE. Liu et al. [27] observed the effects of $\varepsilon$-polylysine and nisin on the changes in $\mathrm{Na}^{+} / \mathrm{K}^{+}$-ATPase activity in Bacillus subtilis when
$\mathcal{E}$-polylysine and nisin were added, where $\mathrm{Na}^{+} / \mathrm{K}^{+}$-ATPase activity decreased. ATPase was inhibited when added in the presence of the $\varepsilon$-polylysine and/or nisin. In addition, Wang et al. [24] demonstrated that chlorine dioxide can inhibit the ATPase activity of Nosema bombycis spores, which destroyed the inner structure of the spores. Thus, cell membrane dysfunction induces the depolarization of the cytoplasmic membrane and leads to a rapid termination of all biosynthetic processes [28].

3.3. Key Enzymatic Activities in Glycolysis Pathway. PK and $\mathrm{HK}$ are key enzymes in glycolysis, which is an important pathway for cellular energy metabolism and biosynthesis. The utilization of glycolytic enzymes also enables the controlled production of pyruvate and acetaldehyde, which are vital for synthesizing other biomolecules [29]. The effects of BPCE on the activities of $\mathrm{HK}$ and $\mathrm{PK}$ in E. coli and $S$. aureus cells are shown in Figure 3. For E. coli, although the HK activity of the treatment group was higher than that of the control, the final HK activity in treatment group was blocked when BPCE was added (Figure 3(a)). A similar variation was observed in the PK groups (Figure 3(b)). HK activity in the $S$. aureus treatment group slightly changed during the first $8 \mathrm{~h}$, whereas the $\mathrm{HK}$ activity in the control group significantly increased within the initial $4 \mathrm{~h}$ and then decreased. Subsequently, the groups exhibited similar changing trends (Figure 3(c)). The PK activity slightly changed in the treatment group, whereas remarkable variations were observed in the control group. For bacterial growth, PK activity reached $424.2 \mathrm{U} / \mathrm{g}$ protein. A lower HK activity resulted in an impaired oxidation of glucose via glycolysis and decreased ATP production. The observed decline in PK activity in bacteria was responsible for the reduced glycolysis and amplified gluconeogenesis, indicating that these two pathways were disrupted [30]. These results suggested that BPCE affected glycolysis, which decreased the synthesis of energetic substances and vital intermediate materials, such as ATP and pyruvate. 


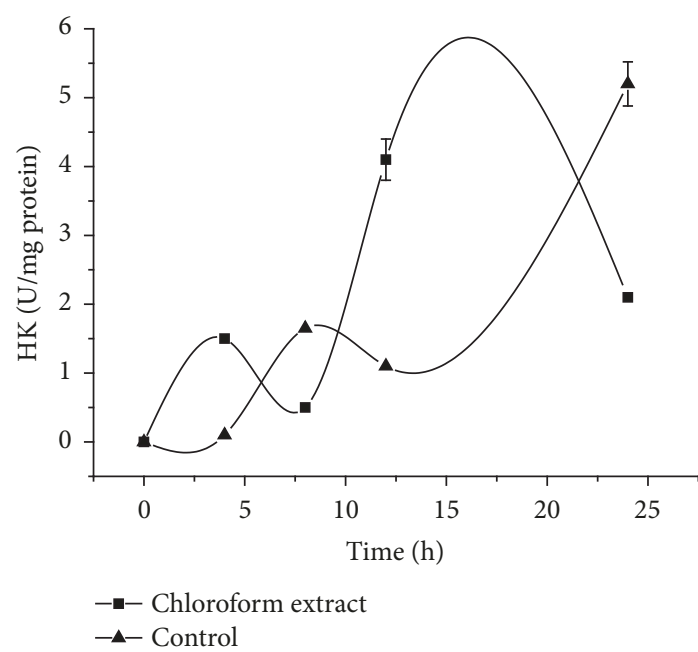

(a)

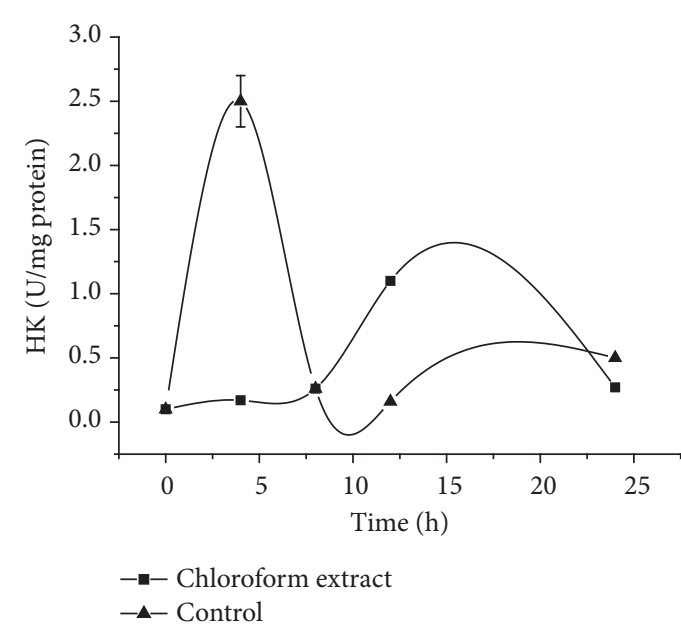

(c)

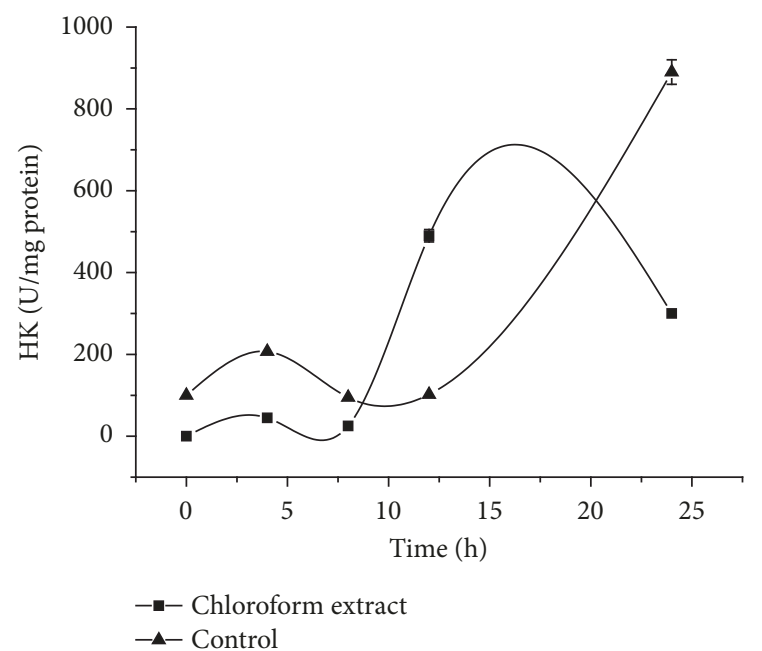

(b)

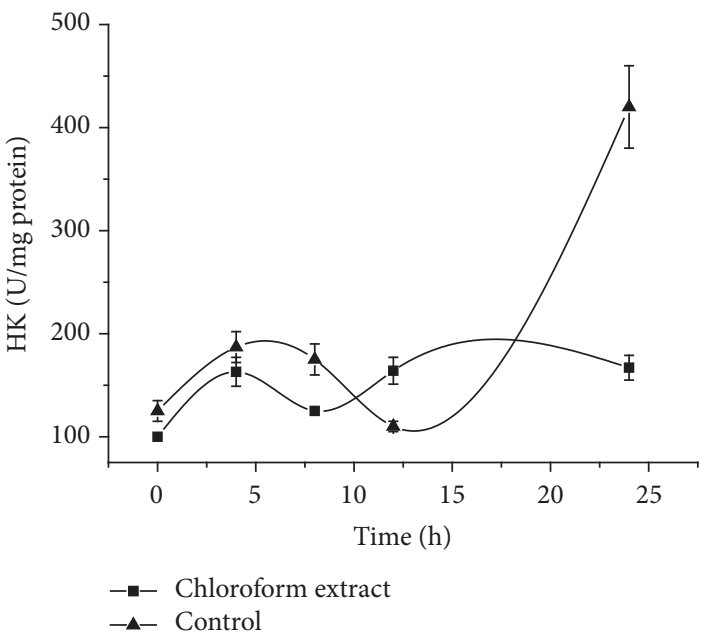

(d)

FIgUre 3: Activities of key enzymes in E. coli (a, b) and S. aureus (c, d).

3.4. Lactic Acid Content. LA is produced by glucose oxidation when available oxygen is insufficient for a microorganism to perform aerobic respiration. The LA content in the treatment group slightly changed when BPCE was added to both bacteria (Figures 4(a) and 4(b)). In comparison, the LA content in the control group increased initially before severely decreasing in E. coli cells (Figure 4(a)), which was similarly observed in $S$. aureus. However, the LA content of $S$. aureus decreased (Figure 4(b)). The large amount of LA in the treatment cells indicated that aerobic respiration was inhibited in the presence of BPCE, indicating that the TCA cycle was hindered. Thus, the bacterial cells obtained energy though anaerobic respiration to maintain their growth. Additionally, LA cannot normally accumulate in cells. However, LA only slightly decreased in our experiments. Moreover, high LA concentration inhibited bacterial cell growth, resulting in bacterial cell death $[31,32]$. These findings were consistent with our previous report, in which BPCE treatment of cells led to the accumulation of pyruvate and inhibited the TCA cycle in bacterial cell respiration [14].
3.5. GC-MS Analysis of the Chemical Composition of BPCE. The results of a GC-MS analysis of the constituents of BPCE identified 152 chemical constituents (presented in Figure 5), and the 41 primary substances are presented in Table 1 . The results revealed that $1 \mathrm{H}$-cycloprop[e] azulen-7-ol, decahydro-1,1,7-trimethyl-4-methylene-, [1ar-(1a $\alpha, 4 \mathrm{a} \alpha, 7 \beta$, $7 \mathrm{a}, \beta, 7 \mathrm{~b} \alpha)].-(8.39 \%)$ and 2-methylene-4,8,8-trimethyl-4vinyl-bicyclo[5.2.0]nonane $(6.92 \%)$ were the two primary components of BPCE. In addition, BPCE was rich in olefinic acids [n-hexadecanoic acid (5.12\%), trans-2-octadecenoic acid (4.90\%), 10,13-octadecadienoic acid (4.89\%), 6octadecenoic acid (4.88\%), 9,12-octadecadienoic acid (Z,Z)(3.11\%), 4-hexadecenoic acid (1.34\%), cis-13-octadecenoic acid (0.90\%), 13-eicosenoic acid (0.58\%), and cis-2dicarboxylic acid $(0.84 \%)]$, alkenes, or oxygenated alkenes [cyclohexene $(0.69 \%), \alpha$-copaene $(0.98 \%)$, caryophyllene oxide $(4.11 \%)$, and alloaromadendrene oxide $(3.53 \%)]$, esters [ethyl 6,9,12-hexadecatrienoate $(0.81 \%)$, hexadecanoic acid methyl ester $(0.91 \%)$, octadecanoic acid ethyl ester $(0.92 \%)$, ethyl oleate $(3.64 \%)$, ethyl cis-9, trans-11-octadecadienoate 


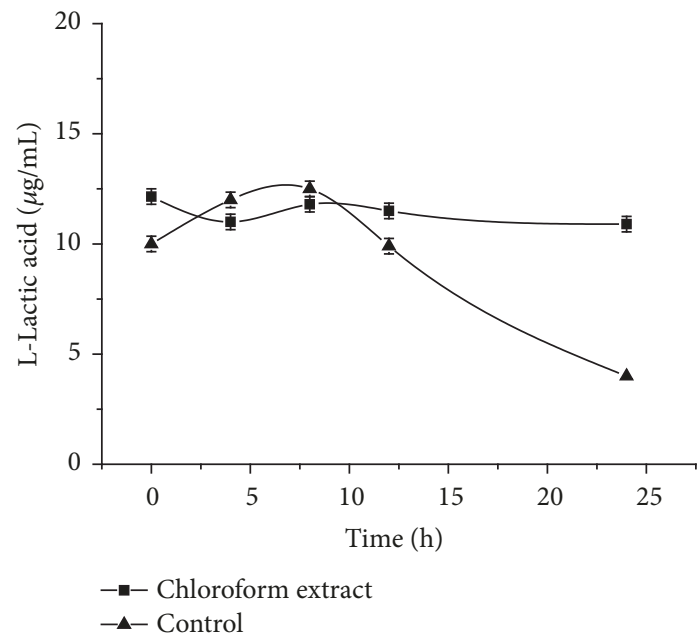

(a)

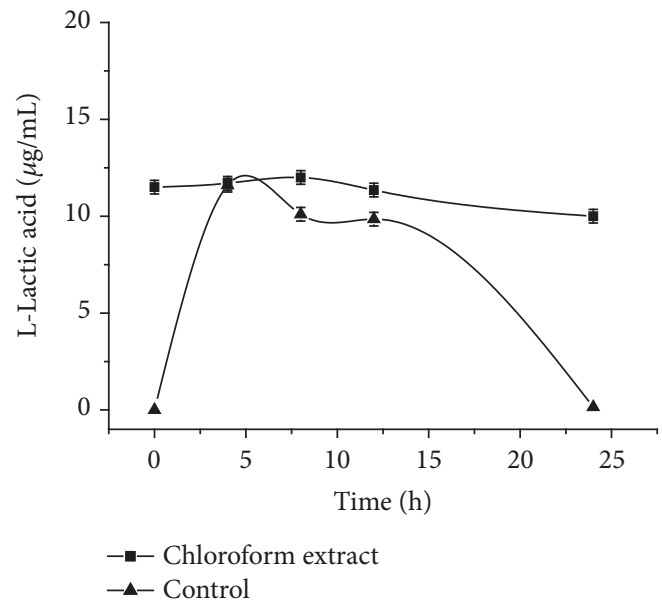

(b)

Figure 4: Lactic acid (LA) content in E. coli (a) and S. aureus (b).

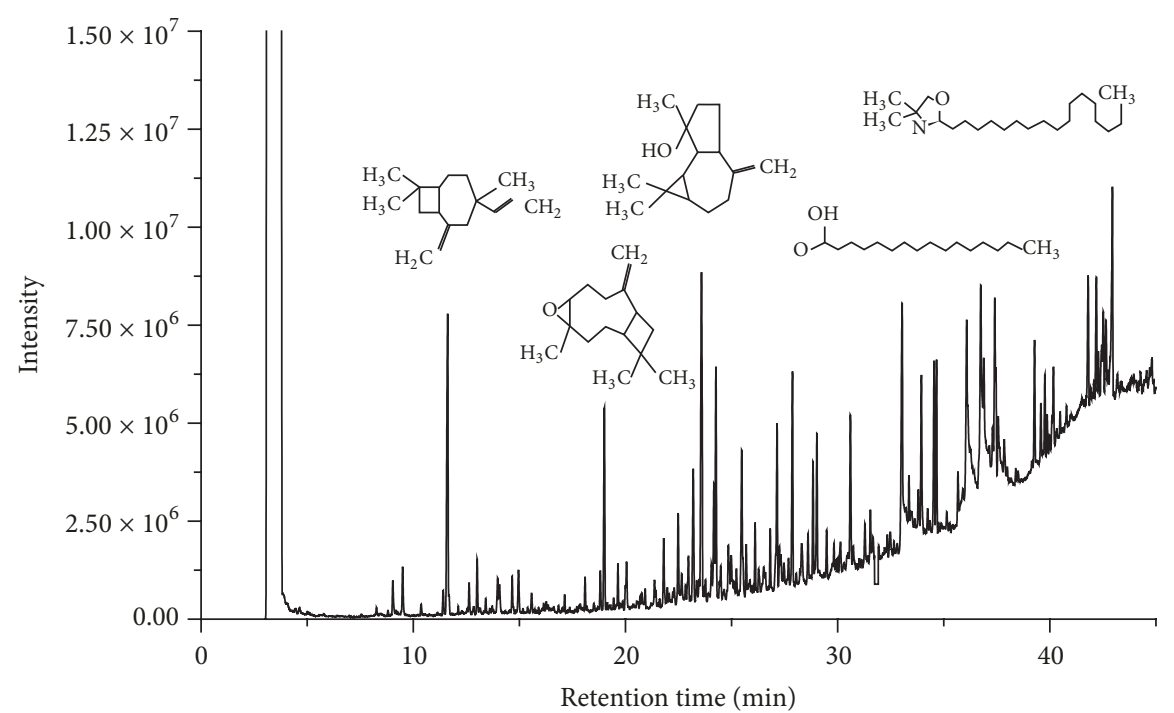

FIGURE 5: GC-MS profile of BPCE.

(4.00\%), ethyl 9,12,15-octadecatrienoate (1.91\%), isonipecotic acid, N-acryloyl-, undecyl ester (0.93\%), and furan-2-carboxylic acid 2,2,6,6-tetramethyl-4-(2,2,2-trifluoro-acetylamino)piperidin-1-yl ester (1.52\%)] and piperonal (3.06\%). A previous study assessed the antimicrobial activity of the volatile oil from Fusarium tricinctum, containing $12.0 \%$ 2-methylene-4,8,8-trimethyl-4-vinyl bicyclo[5.2.0] nonane, against eight bacteria and two fungi [33]. In addition, some alkenes, such as caryophyllene oxide [34], alloaromadendrene oxide [35], and $\alpha$-copaene [36], showed strong antibacterial activity.

\section{Conclusion}

The results of this study showed that $1 \mathrm{H}$-cycloprop[e]azulen7-ol, decahydro-1,1,7-trimethyl-4-methylene-, [1ar-(1a $\alpha, 4 \mathrm{a} \alpha$, $7 \beta, 7 \mathrm{a}, \beta, 7 \mathrm{~b} \alpha$.)]- (8.39\%) and 2-methylene-4,8,8-trimethyl-4vinyl-bicyclo[5.2.0]nonane $(6.92 \%)$ were the two primary components of BPCE. The antibacterial activity of BPCE primarily occurred via two pathways. The first pathway was the alteration of membrane potential and inhibition peptide or protein synthesis. The second pathway involved the hindering of metabolic pathways, such as glycolysis and the TCA cycle. Based on the results, the following antibacterial mechanism of BPCE is proposed: BPCE rapidly destroys bacterial cell walls and membranes and decreases the ATPase level. This phenomenon resulted in a remarkably rapid loss in cell contents, such as transaminase proteins, polysaccharides, and ions. The active ingredients of BPCE entered the cells and interacted with key glycolysis enzymes, eventually hindering and disrupting cell metabolism. Furthermore, an accumulation of LA indicated that bacteria obtained ATP through anaerobic respiration, probably because BPCE blocked the TCA cycle and weakened the electron transport chain to generate ATP. The results of the current investigation will facilitate the development of antibacterial agents targeting 
TABLE 1: The chemical components of BPCE.

\begin{tabular}{|c|c|c|c|}
\hline NO. & Name of compound & $\mathrm{RT}(\min )$ & Area $\%$ \\
\hline (1) & Cyclohexene, 4-ethenyl-4-methyl-3-(1-methylethenyl)-1-(1-methylethyl)-, (3R-trans)- & 8.959 & 0.69 \\
\hline (2) & $\alpha$-Copaene & 9.406 & 0.98 \\
\hline (3) & 2-Methylene-4,8,8-trimethyl-4-vinyl-bicyclo[5.2.0]nonane & 11.622 & 6.92 \\
\hline (4) & 1,4,7,-Cycloundecatriene, 1,5,9,9-tetramethyl-, Z,Z,Z- & 13.010 & 0.97 \\
\hline (5) & 1-Piperidinecarboxaldehyde & 14.959 & 0.93 \\
\hline (6) & Caryophyllene oxide & 19.006 & 4.11 \\
\hline (7) & Ethyl 6,9,12-hexadecatrienoate & 20.051 & 0.81 \\
\hline (8) & 1,3,3-trimethyl-2-Oxabicyclo[2.2.2] octan-6-ol & 22.482 & 1.60 \\
\hline (9) & Hexadecanoic acid, methyl ester & 22.968 & 0.91 \\
\hline$(10)$ & Piperonal & 23.193 & 3.06 \\
\hline (11) & 1H-Cycloprop[e]azulen-7-ol, decahydro-1,1,7-trimethyl-4-methylene-, [1ar-(1a $\alpha, 4 \mathrm{a} \alpha, 7 \beta, 7 \mathrm{a}, \beta, 7 \mathrm{~b} \alpha)]-$. & 23.584 & 8.39 \\
\hline$(12)$ & 4,4-dimethyl-tetracyclo[6.3.2.0(2,5).0(1,8)]tridecan-9-ol & 24.167 & 1.29 \\
\hline (13) & Tricyclo[5.2.2.0(1,6)] undecan-3-ol, 2-methylene-6,8,8-trimethyl- & 24.262 & 3.94 \\
\hline (14) & Alloaromadendrene oxide-(1) & 25.477 & 3.53 \\
\hline$(15)$ & (+-)-1-Isopropylcyclopropane-trans-1,cis-2-dicarboxylic acid & 25.689 & 0.84 \\
\hline$(16)$ & Octadecanoic acid, ethyl ester & 26.821 & 0.92 \\
\hline (17) & Ethyl oleate & 27.144 & 3.64 \\
\hline (18) & Ethyl 9.cis.,11.trans.-octadecadienoate & 27.871 & 4.00 \\
\hline (19) & Vanillin lactoside & 28.302 & 0.83 \\
\hline$(20)$ & n-Tetracosanol-1 & 28.600 & 0.83 \\
\hline$(21)$ & Ethyl 9,12,15-octadecatrienoate & 28.840 & 1.91 \\
\hline$(22)$ & Phytol & 29.020 & 2.45 \\
\hline$(23)$ & $\begin{array}{l}\text { 1H-Cycloprop[e]azulen-7-ol, decahydro-1,1,7-trimethyl-4-methylene-, } \\
\text { [1ar-(1a.alpha.,4a.alpha.,7.beta.,7a.beta.,7b.alpha.)]- }\end{array}$ & 30.599 & 2.81 \\
\hline$(24)$ & n-Hexadecanoic acid & 33.037 & 5.12 \\
\hline$(25)$ & Naphthalene, decahydro-2,2-dimethyl- & 33.36 & 0.63 \\
\hline$(26)$ & 1-(1-(2-Thienyl)cyclohexyl)pyrrolidine & 33.948 & 2.85 \\
\hline$(27)$ & (8R,Z)-8-Methyl-6-((R)-2-methylpentylidene)octahydroindolizine & 34.544 & 3.17 \\
\hline$(28)$ & 2-Ethyl-5-undecyl-. .1 - -pyrroline & 34.662 & 3.02 \\
\hline (29) & 6-Octadecenoic acid & 36.080 & 4.88 \\
\hline$(30)$ & 9,12-Octadecadienoic acid (Z,Z)- & 36.744 & 3.11 \\
\hline$(31)$ & (3S,5R,7aS)-3-(But-3-en-1-yl)-5-(hex-5-en-1-yl)hexahydro-1H-pyrrolizine & 36.889 & 1.12 \\
\hline$(32)$ & Piperidine, 1-(1-oxo-3-phenyl-2-propenyl)- & 37.403 & 1.62 \\
\hline$(33)$ & 2-Cyclohexen-3-ol-1-one, 2-[1-iminotetradecyl]- & 39.279 & 2.21 \\
\hline$(34)$ & Isonipecotic acid, $\mathrm{N}$-acryloyl-, undecyl ester & 39.574 & 0.93 \\
\hline$(35)$ & 4-Hexadecenoic acid, pyrrolidide & 39.763 & 1.34 \\
\hline$(36)$ & cis-13-Octadecenoic acid, 4,4-dimethyloxazoline derivative & 40.171 & 0.90 \\
\hline$(37)$ & trans-2-Octadecenoic acid & 41.804 & 4.90 \\
\hline$(38)$ & 13-Eicosenoic acid, pyrrolidide & 42.444 & 0.58 \\
\hline (39) & Furan-2-carboxylic acid 2,2,6,6-tetramethyl-4-(2,2,2-trifluoro-acetylamino)-piperidin-1-yl ester & 42.520 & 0.88 \\
\hline$(40)$ & 4,5,6,7-Tetrahydrobenz[z]isoxazole-5-ol-4-one, 3-[9-tridecenyl]- & 42.650 & 1.52 \\
\hline$(41)$ & 10,13-Octadecadienoic acid & 42.950 & 4.89 \\
\hline
\end{tabular}

bacterial energy metabolism. However, further studies are needed to determine whether antibacterial agents affect the transcriptome. The experimental results also provided a basis to develop promising natural antimicrobial agents with potential applications in manufacturing industries.

\section{Additional Points}

Highlights. (1) The antimicrobial mechanism of action of black pepper chloroform extract (BPCE) was investigated. (2) Bacterial intracellular transaminases and $\mathrm{Na}^{+} / \mathrm{K}^{+}$-ATPase 
activity were inhibited by BPCE. (3) Bacterial cell walls and membranes were degraded in response to BPCE. (4) The normal metabolism of bacteria was disrupted by BPCE.

\section{Disclosure}

The authors alone are responsible for the content and writing of the paper.

\section{Conflicts of Interest}

The authors report no conflicts of interest.

\section{Authors' Contributions}

Wenxue Chen and Haiming Chen conceived and designed the experiments; Lan Zou performed the experiments; Yueying $\mathrm{Hu}$ and Weijun Chen analyzed the data; Wenxue Chen and Haiming Chen wrote the paper.

\section{Acknowledgments}

This research was supported by the National Natural Science Foundation of China (CN) (31760480, 31640061), Hainan Natural Science Foundation of China (317002), and the Hainan University Start-up Scientific Research Projects of China (ID: kyqd1224; kyqd1630).

\section{References}

[1] M. Marino, C. Bersani, and G. Comi, "Impedance measurements to study the antimicrobial activity of essential oils from Lamiaceae and Compositae," International Journal of Food Microbiology, vol. 67, no. 3, pp. 187-195, 2001.

[2] J. Gutierrez, G. Rodriguez, C. Barry-Ryan, and P. Bourke, "Efficacy of plant essential oils against foodborne pathogens and spoilage bacteria associated with ready-to-eat vegetables: antimicrobial and sensory screening," Journal of Food Protection, vol. 71, no. 9, pp. 1846-1854, 2008.

[3] M. R. Moreira, A. G. Ponce, C. E. Del Valle, and S. I. Roura, "Inhibitory parameters of essential oils to reduce a foodborne pathogen," LWT- Food Science and Technology, vol. 38, no. 5, pp. 565-570, 2005.

[4] Y. Pan, Z. Zhu, Z. Huang et al., "Characterisation and free radical scavenging activities of novel red pigment from Osmanthus fragrans' seeds," Food Chemistry, vol. 112, no. 4, pp. 909-913, 2009.

[5] Y. Pan, C. He, H. Wang, X. Ji, K. Wang, and P. Liu, "Antioxidant activity of microwave-assisted extract of Buddleia officinalis and its major active component," Food Chemistry, vol. 121, no. 2, pp. 497-502, 2010.

[6] M. S. Butt, I. Pasha, M. T. Sultan, M. A. Randhawa, F. Saeed, and W. Ahmed, "Black Pepper and Health Claims: A Comprehensive Treatise," Critical Reviews in Food Science and Nutrition, vol. 53, no. 9, pp. 875-886, 2013.

[7] Y. C. Yoon, S.-H. Kim, M. J. Kim, H. J. Yang, M.-R. Rhyu, and J.-H. Park, "Piperine, a component of black pepper, decreases eugenol-induced cAMP and calcium levels in nonchemosensory 3T3-L1 cells," FEBS Open Bio, vol. 5, pp. 20-25, 2015.
[8] S. Dutta and P. Bhattacharjee, "Enzyme-assisted supercritical carbon dioxide extraction of black pepper oleoresin for enhanced yield of piperine-rich extract," Journal of Bioscience and Bioengineering, vol. 120, no. 1, pp. 17-23, 2015.

[9] E. D. Roberson and L. Mucke, "100 Years and counting: prospects for defeating Alzheimer's disease," Science, vol. 314, no. 5800, pp. 781-784, 2006.

[10] H. J. D. Dorman and S. G. Deans, "Antimicrobial agents from plants: antibacterial activity of plant volatile oils," Journal of Applied Microbiology, vol. 88, no. 2, pp. 308-316, 2000.

[11] N. M. A. Chaudhry and P. Tariq, "Bactericidal activity of black pepper, bay leaf, aniseed and coriander against oral isolates.", Pakistan journal of pharmaceutical sciences., vol. 19, no. 3, pp. 214-218, 2006.

[12] A. Thiel, C. Buskens, T. Woehrle et al., "Black pepper constituent piperine: Genotoxicity studies in vitro and in vivo," Food and Chemical Toxicology, vol. 66, pp. 350-357, 2014.

[13] K. J. Pradhan, P. S. Variyar, and J. R. Bandekar, "Antimicrobial activity of novel phenolic compounds from green pepper (Piper nigrum L.)," LWT- Food Science and Technology, vol. 32, no. 2, pp. 121-123, 1999.

[14] L. Zou, Y.-Y. Hu, and W.-X. Chen, "Antibacterial mechanism and activities of black pepper chloroform extract," Journal of Food Science and Technology, vol. 52, no. 12, pp. 8196-8203, 2015.

[15] M. C. Soria and M. C. Audisio, "Inhibition of Bacillus cereus Strains by Antimicrobial Metabolites from Lactobacillus johnsonii CRL1647 and Enterococcus faecium SM21," Probiotics and Antimicrobial Proteins, vol. 6, no. 3-4, pp. 208-216, 2014.

[16] M. Carina Audisio, M. J. Torres, D. C. Sabaté, C. Ibarguren, and M. C. Apella, "Properties of different lactic acid bacteria isolated from Apis mellifera L. bee-gut," Microbiological Research, vol. 166, no. 1, pp. 1-13, 2011.

[17] C. Korzeniewski and D. M. Callewaert, "An enzyme-release assay for natural cytotoxicity," Journal of Immunological Methods, vol. 64, no. 3, pp. 313-320, 1983.

[18] X. Yao, X. Zhu, S. Pan et al., "Antimicrobial activity of nobiletin and tangeretin against Pseudomonas," Food Chemistry, vol. 132, no. 4, pp. 1883-1890, 2012.

[19] Y.-L. Ma, B. Yang, T. Guo, and L. Xie, "Antibacterial mechanism of $\mathrm{Cu}^{2+}-\mathrm{ZnO} /$ cetylpyridinium-montmorillonite in vitro," Applied Clay Science, vol. 50, no. 3, pp. 348-353, 2010.

[20] N. Sharma and A. Tripathi, "Effects of Citrus sinensis (L.) Osbeck epicarp essential oil on growth and morphogenesis of Aspergillus niger (L.) Van Tieghem," Microbiological Research, vol. 163, no. 3, pp. 337-344, 2006.

[21] M. Tolouee, S. Alinezhad, R. Saberi et al., "Effect of Matricaria chamomilla L. flower essential oil on the growth and ultrastructure of Aspergillus niger van Tieghem," International Journal of Food Microbiology, vol. 139, no. 3, pp. 127-133, 2010.

[22] T. Wu, D. Cheng, M. He, S. Pan, X. Yao, and X. Xu, "Antifungal action and inhibitory mechanism of polymethoxylated flavones from Citrus reticulata Blanco peel against Aspergillus niger," Food Control, vol. 35, no. 1, pp. 354-359, 2014.

[23] F. Cornelius, M. Habeck, R. Kanai, C. Toyoshima, and S. J. D. Karlish, "General and specific lipid-protein interactions in Na,K-ATPase," Biochimica et Biophysica Acta (BBA) - Biomembranes, vol. 1848, no. 9, pp. 1729-1743, 2015.

[24] Z. Wang, F. Liao, J. Lin et al., "Inactivation and mechanisms of chlorine dioxide on Nosema bombycis," Journal of Invertebrate Pathology, vol. 104, no. 2, pp. 134-139, 2010. 
[25] J. D. Berg, P. V. Roberts, and A. Matin, "Effect of chlorine dioxide on selected membrane functions of Escherichia coli," Journal of Applied Bacteriology, vol. 60, no. 3, pp. 213-220, 1986.

[26] M. V. Zamaraeva, R. Z. Sabirov, E. Maeno, Y. Ando-Akatsuka, S. V. Bessonova, and Y. Okada, "Cells die with increased cytosolic ATP during apoptosis: A bioluminescence study with intracellular luciferase," Cell Death \& Differentiation, vol. 12, no. 11, pp. 1390-1397, 2005.

[27] H. Liu, H. Pei, Z. Han, G. Feng, and D. Li, "The antimicrobial effects and synergistic antibacterial mechanism of the combination of $\varepsilon$-Polylysine and nisin against Bacillus subtilis," Food Control, vol. 47, pp. 444-450, 2015.

[28] H.-G. Sahl, M. Kordel, and R. Benz, "Voltage-dependent depolarization of bacterial membranes and artificial lipid bilayers by the peptide antibiotic nisin," Archives of Microbiology, vol. 149, no. 2, pp. 120-124, 1987.

[29] T. Nakamura, Y. Kashima, S. Mine, T. Oku, and K. Uegaki, "Characterization and crystal structure of the thermophilic ROK hexokinase from Thermus thermophilus," Journal of Bioscience and Bioengineering, vol. 114, no. 2, pp. 150-154, 2012.

[30] V. Ramachandran and R. Saravanan, "Efficacy of asiatic acid, a pentacyclic triterpene on attenuating the key enzymes activities of carbohydrate metabolism in streptozotocin-induced diabetic rats," Phytomedicine, vol. 20, no. 3-4, pp. 230-236, 2013.

[31] J. A. Reis, A. T. Paula, S. N. Casarotti, and A. L. B. Penna, "Lactic acid bacteria antimicrobial compounds: characteristics and applications," Food Engineering Reviews, vol. 4, no. 2, pp. 124-140, 2012.

[32] C. Axel, B. Röcker, B. Brosnan et al., "Application of Lactobacillus amylovorus DSM19280 in gluten-free sourdough bread to improve the microbial shelf life," Food Microbiology, vol. 47, pp. 36-44, 2015.

[33] Y. Zhang, J. Zhao, J. Wang et al., "Chemical composition and antimicrobial activity of the volatile oil from Fusarium tricinctum, the endophytic fungus in Paris polyphylla var. yunnanensis," Natural Product Communications (NPC), vol. 6, no. 11, pp. 1759-1762, 2011.

[34] D. Yang, L. Michel, J.-P. Chaumont, and J. Millet-Clerc, "Use of caryophyllene oxide as an antifungal agent in an in vitro experimental model of onychomycosis," Mycopathologia, vol. 148, no. 2, pp. 79-82, 1999.

[35] L. Alavi, M. Barzegar, A. Jabbari, and H. Naghdi Badi, "The effect of heat treatment on chemical composition and antioxidant property of Lippia citriodora essential oil," Journal of Medicinal Plants, vol. 10, no. 39, pp. 65-75, 2011.

[36] M. C. Scur, F. G. S. Pinto, J. A. Pandini, W. F. Costa, C. W. Leite, and L. G. Temponi, "Antimicrobial and antioxidant activity of essential oil and different plant extracts of psidium cattleianum sabine," Brazilian Journal of Biology, vol. 76, no. 1, pp. 101-108, 2016. 


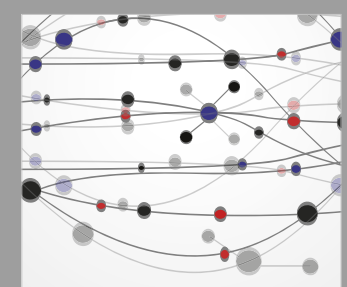

The Scientific World Journal
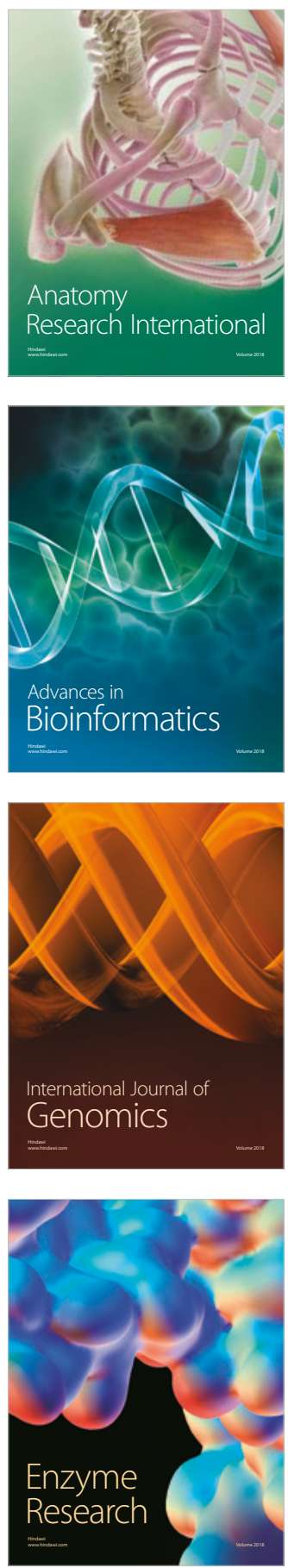
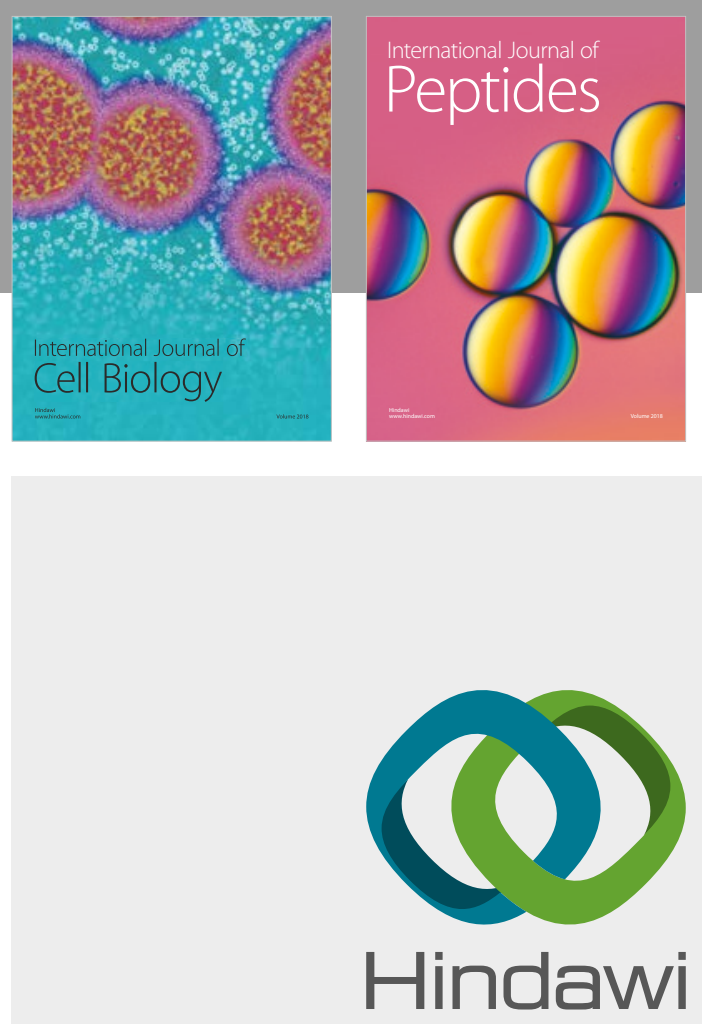

Submit your manuscripts at

www.hindawi.com
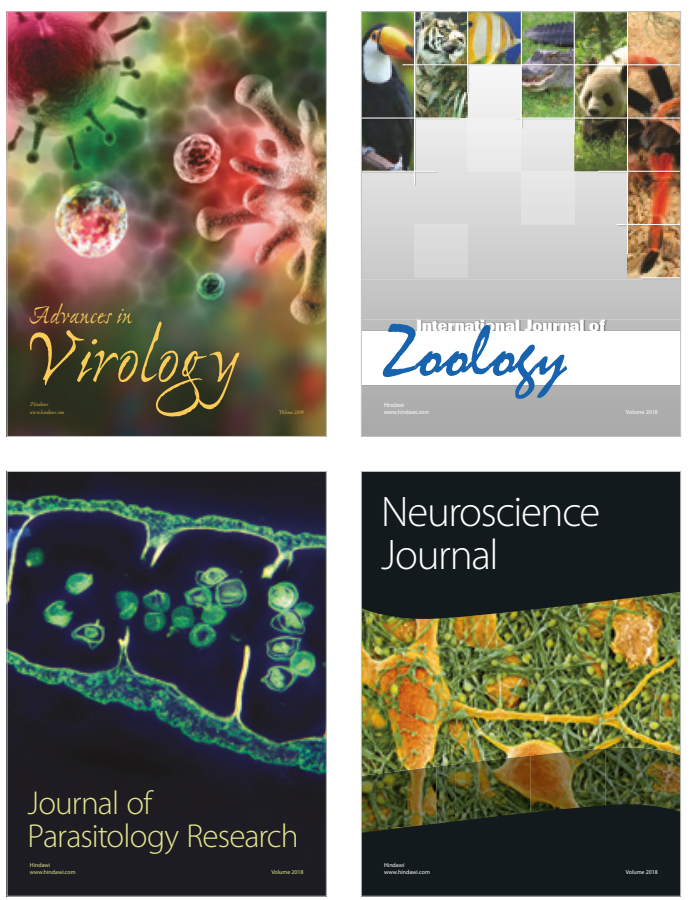
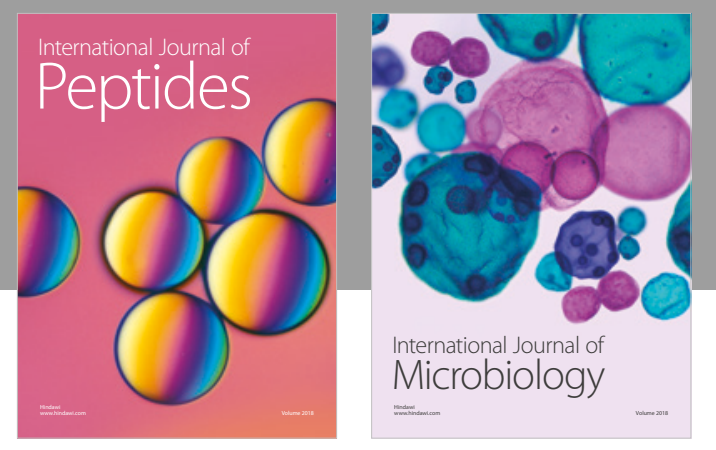

nternational Journal of Microbiology
Journal of
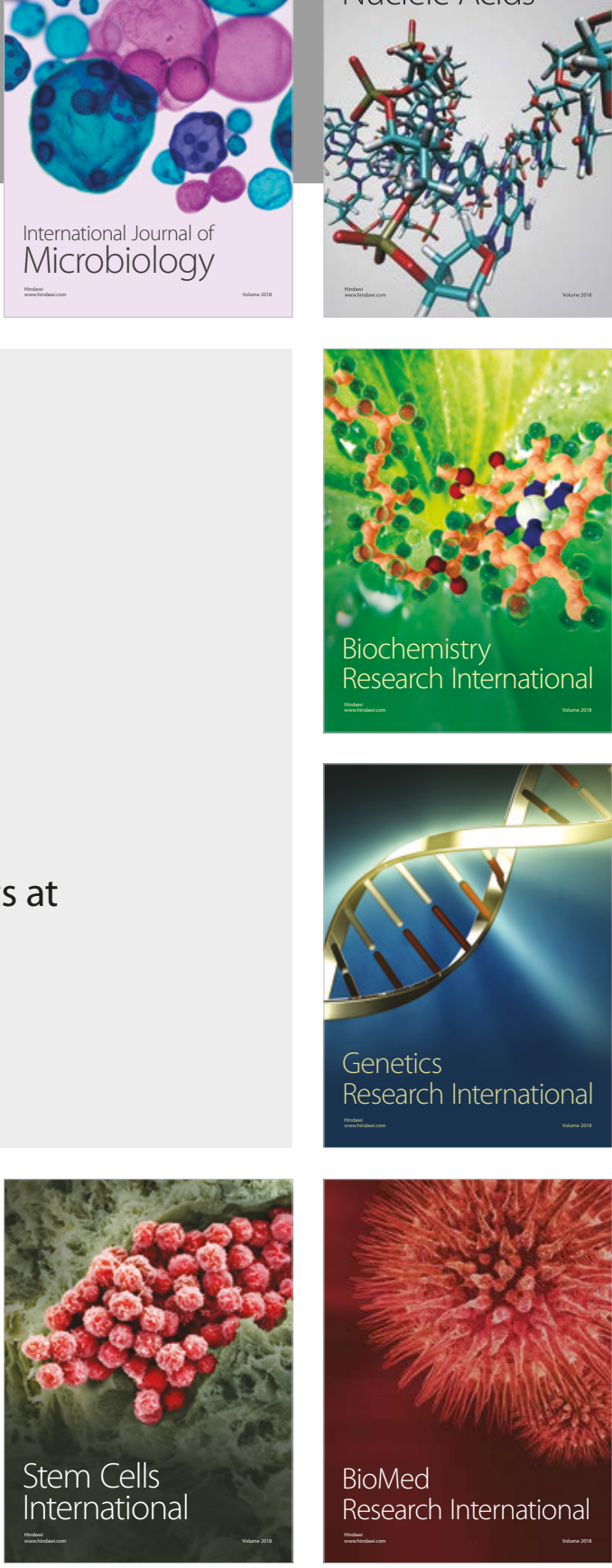
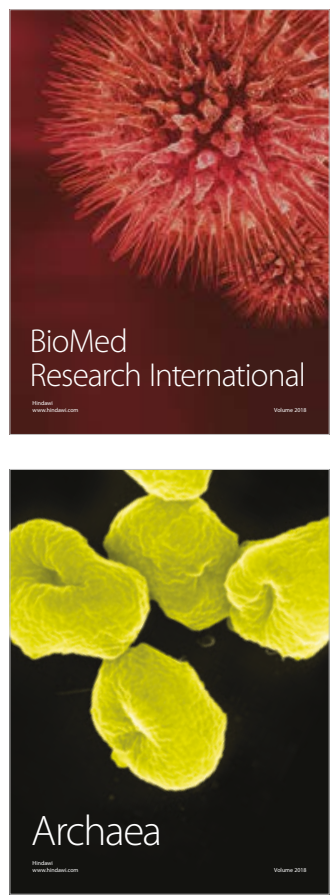